\title{
Management of Langerhans Cell Histiocytosis (LCH)-Induced Central Diabetes Insipidus and Its Associated Endocrinological/Neurological Sequelae
}

\author{
Shinsaku Imashuku ${ }^{1}$ and Akira Morimoto ${ }^{2}$ \\ ${ }^{1}$ Division of Pediatrics, Takasago-seibuHospital, Takasago, \\ 2Department of Pediatrics, JichiMedicalUniversity, Shimotsuke,
}

Japan

\section{Introduction}

Central diabetes insipidus (CDI) is caused by a deficiency of arginine vasopressin (AVP), also known as antidiuretic hormone. Although CDI is rare in children and young adults, it should be kept in mind that it is associated with rare histiocytic disorders in the central nervous system (CNS), namely Langerhans cell histiocytosis $(\mathrm{LCH})$, xanthogranulomatosis and Erdheim-Chester disease, all of which specifically affect the hypothalamus and pituitary stalk, thereby inducing CDI $(\mathbf{1}, \mathbf{2})$. In particular, CDI is the most frequently occurring CNS event in patients with multi-focal $\mathrm{LCH}$, who often have multisystem lesions, including craniofacial bone lesions (3). $\mathrm{LCH}$ is a rare disorder that is characterized by the proliferation of cells that bear the activated Langerhans cell phenotype (4). Early studies reported that CDI occurs in $25-50 \%$ of $\mathrm{LCH}$ patients but this incidence appears to have dropped to $7-20 \%$ since the introduction of systemic chemotherapy (5). CDI can develop either before, simultaneously with, or subsequent to a diagnosis of $\mathrm{LCH}$ based on the presence of various extracranial lesions. It can also develop during chemotherapy for systemic LCH or after therapy. Patients with LCH-induced CDI show typical clinical symptoms, such as polyuria/polydispsia, in association with abnormal radiographic findings, such as a thickened pituitary stalk or a hypothalamic mass and the loss of a hot signal (T1 weighted) for the pituitary posterior lobe on brain magnetic resonance imaging (MRI) (5-8). Once CDI develops, it becomes irreversible in most patients, who will require life-long desmopressin replacement therapy with 1-desamino-8-D-arginine vasopressin(DDAVP). In addition, 30$58 \%$ of patients with CDI exhibit anterior pituitary hormone deficiencies (APHD) during follow-up (1,7). LCH-associated APHD appears to be linked to a thickening of the pituitary stalk $(6,7)$. In addition, patients with LCH-induced CDI can eventually develop neurodegenerative (ND) disease $(\mathbf{9 , 1 0})$.

Appropriate management of LCH-induced CDI involves (a) a prompt correct diagnosis; (b) early intervention with chemo/radiotherapy to reverse the CDI, if possible; (c) appropriately treating CDI to prevent the later development of APHD or ND disease; (d) good control of CDI, once it has become permanent, with DDAVP; and ideally (e) exploring future innovative measures that could prevent the occurrence of CDI in patients with $\mathrm{LCH}$. 


\section{Diagnosis of LCH-related CDI}

\subsection{Risk factors associated with the development of CDI}

CDI occurs most often among pediatric patients with multi-focal $\mathrm{LCH}$, particularly those with multi-system disease with proptosis (11). Moreover, $\mathrm{LCH}$ lesions in the craniofacial bones are seen in $>75 \%$ of CDI patients (7). We also found that LCH-induced CDI is associated significantly more frequently $(p<0.001)$ with multi-system multi-focal bone lesions, particularly lesions in craniofacial bones (temporal bone, ear-petrous bone, orbita, and zygomatic bone), than with single system bone lesions (12).

\subsection{Diagnosis of CDI}

CDI is generally suspected on the basis of the characteristic symptoms of polyuria/polydipsia. To correctly diagnose CDI, the water deprivation with desmopression test has long been employed $(\mathbf{1 3}, \mathbf{1 4})$. At diagnosis, to confirm that CDI has developed, it is necessary to determine plasma osmolality (reference values, 276-292 mOsm/ $\mathrm{kg} \mathrm{H}_{2} \mathrm{O}$ ) together with plasma AVP levels (reference values, $0.3-4.2 \mathrm{pg} / \mathrm{ml}$ by RIA 2 antibody method). The plasma osmolarity, AVP, and water deprivation test data are important for the early diagnosis of partial CDI, which is critical for preventing the progression into permanent CDI. However, sequential plasma osmolarity, AVP, and water deprivation test data are not available from the pre-CDI period to partial CDI and to complete CDI phase for patients.

CDI may occur before, simultaneously with, or subsequent to a diagnosis of LCH that is made on the basis of biopsies of extra-cranial peripheral lesions such as those in the skin, bone, and soft tissues. The definite diagnosis of LCH is made on the basis of histopathology of granulomatous lesions that reveals the presence of CD1a-, Langerin (CD207)- and S100positive cells (15). If the initial and only lesion in patients with CDI is a thickened stalk, it may be necessary to biopsy the stalk since it has been reported that pituitary stalk thickening precedes the typical peripheral lesions of LCH by several months (16). However, the decision to biopsy should be made carefully, but it must be done promptly. The diagnosis and treatment of such cases are often delayed because physicians tend to follow a "wait and see" policy.

\subsection{Differential diagnosis}

CDI has various etiologies. Some are idiopathic while others are mass lesions on the hypothalamic-pituitary axis caused by germinoma, histiocytic disorders (including LCH),

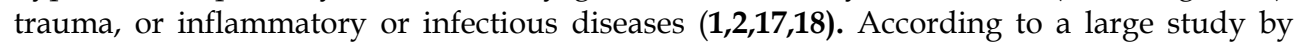
Maghnie et al.(1), the etiologies in 52\% of CDI cases were idiopathic, while LCH accounted for another $15 \%$. It should be noted that LCH should be suspected first in children with CDI, and that about $70 \%$ show pituitary stalk thickening while the remaining $30 \%$ may demonstrate a hypothalamic mass. In contrast, in adults, CDI is more frequently caused by inflammatory processes such as sarcoidosis or tuberculosis and neoplastic infiltrations that do not originate from neuronal tissue (2). Another possible cause in adults is lymphocytic hypophysitis, which is also termed infundibulo-neurohypophysitis or lymphocytic infundibulo-neurohypophysitis (19). Whenever this is suspected, the diagnosis is often delayed because a "wait and see" policy is adopted; this is because the disease is thought to be essentially self-limited. 


\subsection{Radiographic findings}

Abnormal radiographic findings that are associated with CDI are a thickened pituitary stalk or hypothalamic mass and the loss of a hot signal (on T1-weighted MRI) in the pituitary posterior lobe (Figure 1, 2). According to Grois et al. (7), by the time CDI is diagnosed in LCH patients, $71 \%$ already exhibit a thickened stalk, while MRIs performed more than 5 years after CDI onset show that the stalk is still thickened in $24 \%$ of patients. Also, in a small percentage of patients, the stalk was already thickened several months before CDI onset. In addition, in the study of Maghnie et al. (1), where CDI cases with various etiologies were reviewed, 37\% exhibited thickening of the pituitary stalk on the first MRI scan and, in $94 \%$, the posterior pituitary was not hyper-intense. Moreover, when the course of CDI was examined in 18 patients who had a normal or thickened pituitary stalk at presentation, changes in the thickness of the stalk were observed over time: these included normalization, a decrease in thickness, further thickening, and thickening of a previously normal stalk Regarding the loss of the hot spot in the posterior pituitary lobe, we have often found it difficult to interpret the T1-weighted MRI findings because the hot signal in the posterior lobe is masked or overlapped by the hot signal of the dorsum sellae. This problem can be overcome if the slice on MRI is performed appropriately so that the posterior pituitary and the dorsum sellae are separated $(\mathbf{8 , 2 0})$ (Figure 1). The high signal in the posterior lobe is due to the retention of AVP (8), while the high signal in the dorsum sellae reflects the dura membrane that covers the thin bony dorsum sellae. It has been suggested that the fat suppression technique and a horizontal direction of frequency encoding could help to differentiate the high signal of the neurohypophysis from that of the dorsum sella (20). In
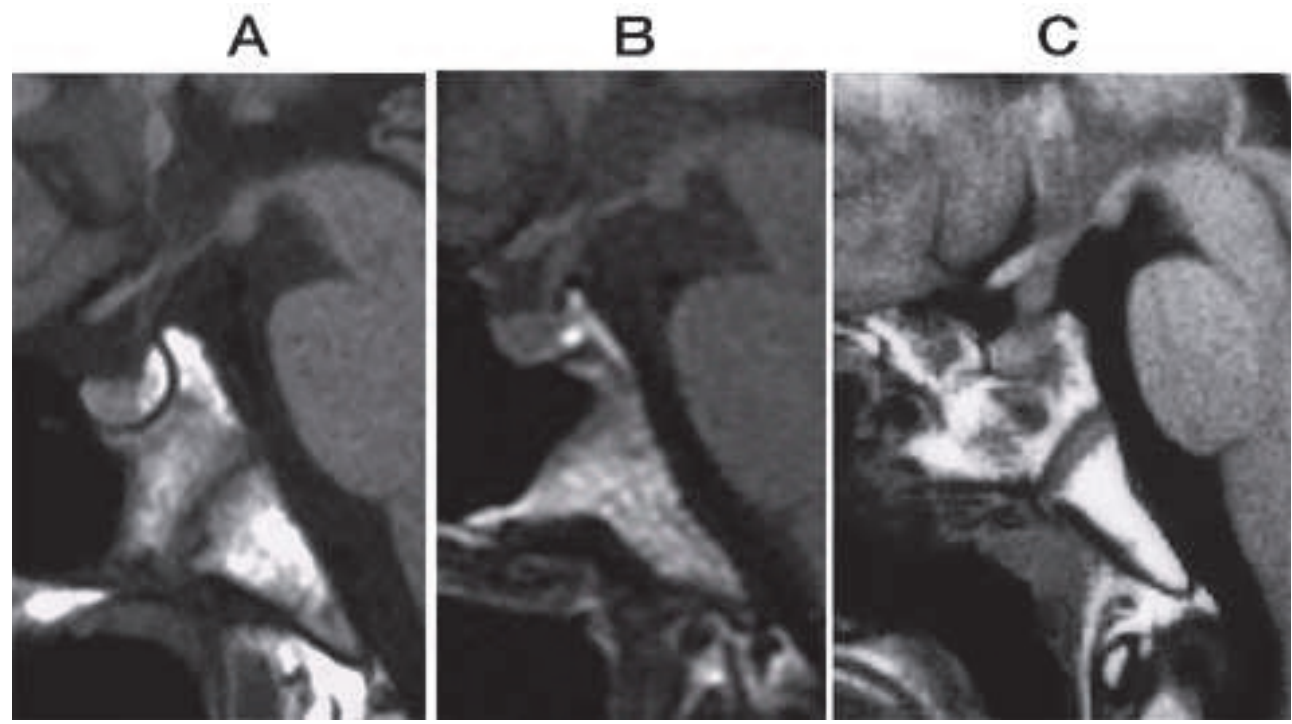

Fig. 1. MRI reveals normal and abnormal hypothalamic-pituitary regions. In two healthy controls, a hot signal in the pituitary lobe that is clearly separated from the dorsum sella can be observed (A,B: T1-weighted). A patient with LCH shows a thickened stalk and the loss of the hot spot in the posterior lobe (C: T1-weighted). 


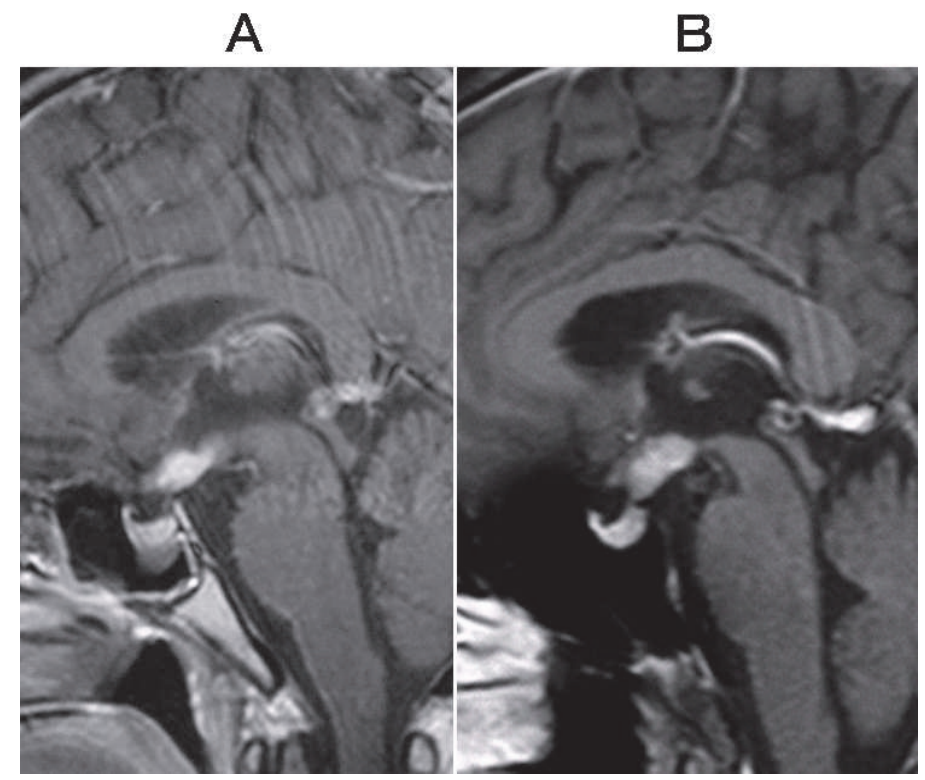

Fig. 2. Gadolinium-enhanced MRIs show a hypothalamic mass in two patients with LCH (A, B), each of which was histopathologically confirmed to be LCH by biopsy.

addition, it is recommended that to confirm the diagnosis of CDI in patients with polyuria/polydipsia, an early survey of the hypothalamic-pituitary axis by Gadoliniumenhanced MRI should be performed (Figure 2).

\subsection{CDI-related CNS complications - Anterior Pituitary Hormone Deficiencies (APHD) and Neurodegenerative (ND) Disease}

LCH-induced hypopituitarism has been described in children as well as in adults (21-24). Clinically, the symptoms start with CDI and then progress to anterior pituitary dysfunction, particularly growth hormone insufficiency. The 10-year risk of developing growth hormone deficiency is $54 \%$ in pediatric patients (25). However, sex hormone deficiency or hypogonadism has also been reported in both adult-onset cases of LCH and adults with childhood-onset LCH. Kaltsas et al.(23) found that at a median of $4.5 \mathrm{yr}$ after the diagnosis of CDI in 12 adult cases, eight exhibited growth hormone deficiency, seven had FSH-LH deficiency, five showed TSH/ACTH deficiency, and five had panhypopituitarism. Similarly, in ten pediatric LCH cases with CDI, Amato et al.(24) reported growth hormone deficiency in four, obesity in three, and hypogonadism in two. Moreover, Maghnie et al. (1) found that the prevalence of growth hormone deficiency after the onset of CDI was $61 \%$ at a median of 0.6 year after onset (range, 0.1 to 18.0). In advanced cases, panhypopituitarism develops.

LCH-associated ND disease develops in $1-4 \%$ of LCH patients $(9,10)$ but the correlation between CDI and ND disease is not as clear as the correlation between CDI and APHD. Grois et al. (7) reported that $76 \%$ of CDI patients with follow-up MRIs performed at least 5 years after diagnosis exhibited neurodegenerative brain changes, showing a correlation between CDI and ND disease. On the other hand, we have noted in Japan that $50 \%$ of patients with LCH-induced ND disease had CDI but the other half did not (10). MRI is the 
most sensitive and commonly used technique for the diagnosis and monitoring of lesions in the cerebellum and basal ganglia (Figure 3). Symptomatic patients with this disorder show neurological dysfunction such as clumsiness, tremor, dysarthria, dysphagia, nystagmus, dysmetria and ataxia $(\mathbf{9 , 1 0})$. The eventual outcome of ND disease is dismal.
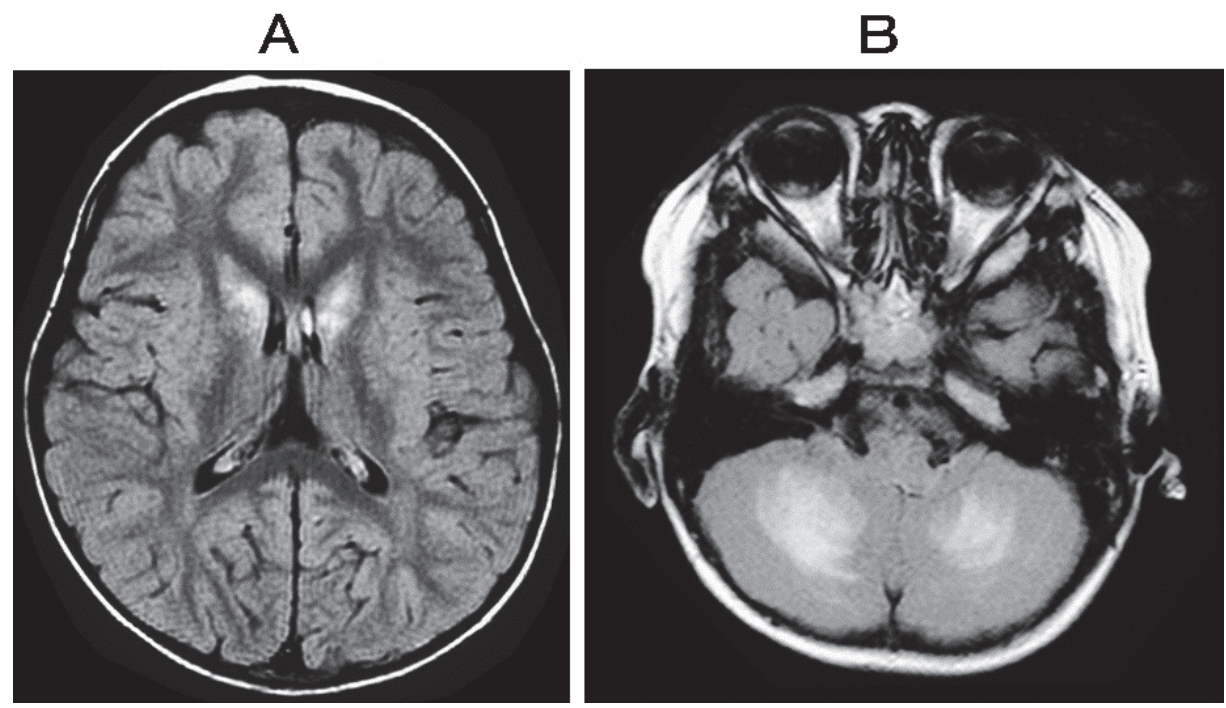

Fig. 3. MRI of patients with neurodegenerative disease after treatment for multifocal LCH show high signals at the basal ganglia (A: Flair, TR=9000) and the cerebellar dentate nuclear area (B: Flair, TR=9000).

\section{Management of LCH-induced CDI}

\subsection{Definition of CDI response to treatment}

Complete response (CR) could be defined as no further need for DDAVP therapy, while partial response (PR) could be defined as a reduction $(>50 \%)$ in the DDAVP dosage. Although Minehan et al. (27) included improvement in computed tomography or MRI findings in their evaluation criteria, Grois et al. (7) concluded that the pituitary stalk thickness changes in a highly variable manner and does not correlate clearly with the treatment outcome.

\subsection{Detection of partial CDI}

Broadbent et al. (13) reported that ten of 14 children with LCH-induced CDI had "complete" CDI at onset, while the other four had "partial" CDI. This suggests that, in some cases of $\mathrm{LCH}$, the early phase of CDI can be detected. Such conditions have also been described as partial, transient, or subclinical CDI. In one trial with $21 \mathrm{LCH}$ patients who did not have CDI and had had LCH for less than four years (11), when the response of urinary AVP to water deprivation was measured every six months, it was found that $24 \%$ had subnormal responses during the initial test and CDI subsequently developed in two. However, it seemed difficult to predict precisely when CDI develops. Notably, Broadbent et al. (13) also 
showed that CDI improved transiently during prednisolone therapy in one case and improved permanently after etoposide therapy in another. In addition, Ottaviano et al. (26) also successfully reversed partial CDI by using 2-chloro-deoxyadenosine (2-CDA). However, preventing the progression from partial CDI to complete CDI by treatment does not seem to be an easy task.

\subsection{Irradiation therapy of CDI}

LCH-induced CDI has been treated with irradiation with or without systemic chemotherapy $(\mathbf{1 3}, \mathbf{2 7}-29)$. In the past, hypothalamic-pituitary radiation therapy (HPRT) was the standard treatment for LCH-induced CDI in adults as well as in children (27). According to Minehan et al. (27), 36\% of their HPRT-treated patients (10/28) responded (22\% CR and $14 \%$ PR), whereas none in the untreated control group responded. It should be noted that five of the six complete responders were irradiated within 14 days of the diagnosis of CDI, and that three of the five patients $(60 \%)$ who were treated with more than 15 Gy responded, as compared to seven of 23 patients $(30 \%)$ who were treated with less than $15 \mathrm{~Gy}$. In addition, eight of the ten responders (80\%) were female, whereas 16 of the 35 non-responders (46\%) were female. Greenberger (28) emphasized that the most important variable in achieving a CR or PR is the speed with which therapy is initiated after the onset of symptoms: it was suggested that therapy should be instituted within 7 days, preferably sooner. However, while these observations indicate the importance and superiority of early intervention with irradiation in CDI, a risk/benefit ratio needs to be determined. In pediatric cases, HPRT is currently not recommended (30) and chemotherapy (such as $2-\mathrm{CDA}$ ) is preferred to irradiation $(\mathbf{2 8 , 3 0 )}$. In addition, prolonged low dose systemic chemotherapy is indicated (30).

\subsection{DDAVP}

A synthetic analog of arginine vasopressin is the drug of choice in the treatment of CDI. Nasal or oral administration of DDAVP, a long-acting vasopressin analog, reduces the daily urinary volume (31). To maintain normal urinary volume and control the symptoms of CDI, 5-20 $\mu \mathrm{g}$ of nasal DDAVP is required per day. As little as $2.5 \mu \mathrm{g}$ may be sufficient, but the usual dose is $5-15 \mu \mathrm{g} /$ day. In oral DDAVP, the tablet contains $100 \mu \mathrm{g}$ of desmopressin acetate and the maximum plasma concentration after a single oral administration of 100 $\mu$ g DDAVP is obtained at $90 \mathrm{~min}$ (31). The average oral DDAVP dose required to obtain good control of CDI is about 20 times higher than the intranasal dose. Subcutaneous DDAVP is also available, which is useful for the treatment of infants with CDI and appears to be superior to oral or intranasal DDAVP therapy (32). Since the major complication of DDAVP therapy is water intoxication and hyponatremia, careful dose titration is required.

\subsection{Optimal measures for APHD and ND disease}

Growth hormone deficiency, thyroid dysfunction, and sex hormone (LH/FSH, testosterone) deficiency should be treated by hormonal replacement. In children, growth hormone deficiency is most common, whereas sex hormone deficiency is more frequent in adults. When the disease progresses into panhypopituitarism, cortisol replacement is also required. To date, while several reports have indicated that CDI can be reversed (as discussed above), this has not been observed for APHD (2,22,23). There is one exception: Makras et al. (33) reported that a 35-year-old female resumed normal menstrual cycling after steroid 
administration. Since the hypothalamic-pituitary space-occupying mass lesions of LCH respond very well to $2-\operatorname{CDA}(\mathbf{2}, \mathbf{2 6}, \mathbf{3 4})$, additional studies are needed to determine whether early administration of 2-CDA could reverse APHD as well as CDI.

Established ND disease is very difficult to treat. Although several reports have suggested that all-trans retinoic acid or a combination of vincristine/AraC and intravenous high dose gamma-globulin (IVIG) may have some efficacy (35-37), it remains unclear whether any specific type of initial systemic chemotherapy for multifocal $\mathrm{LCH}$ patients can limit the later occurrence of ND disease (38). There is an urgent need for research that can identify an innovative therapy for such cases.

\section{CDI and other CNS complications experienced in the Japanese LCH study}

The cases of CDI, APHD and ND disease were analyzed in the cohort of patients treated with the JLSG-96/-02 protocols from 1996 to 2009 in Japan (39). CDI was detected in 12.4\% $(43 / 348)$ of pediatric multifocal LCH patients with a median follow-up of 5.0 (range, $0.2-$ 14.0) years, with the shortest follow-up of alive patients being 0.8 years from the initiation of treatment. Of these 43 cases, CDI was detected before LCH diagnosis in 13 cases, at the LCH diagnosis in 12 cases, during the induction/maintenance treatment in five cases, and after off therapy at a median of 21 months (range, 4-116) in the remaining 12 cases. The incidence of CDI after the initiation therapy was $5.6 \%$ in our JLSG protocols, which is lower than $9.3 \%$ by Grois et al. (5). Data indicate that our treatment protocol effectively reduces the incidence of CDI by preventing the new occurrence. Of the 43 CDI patients, APHD was noted in $30.2 \%$ $(13 / 43)$, with growth hormone deficiency being observed in ten of these patients. Six patients developed ND disease. In total, chemotherapy completely resolved CDI in two patients, which suggests that early intervention with chemotherapy may be able to reverse CDI (39).

\section{Recommendations and future trials}

In practice, when $\mathrm{LCH}$ patients, particularly those with craniofacial bone lesions, are diagnosed, treated and followed up, they must be examined carefully for any signs suggesting that CDI is developing. In particular, inquiring about the symptoms of polydipsia/polyuria and occasional tests for plasma osmolarity with plasma AVP may help to diagnose CDI early after onset. Moreover, in young females, the presence of amenorrhea and/or morbid obesity could be a first sign of pituitary dysfunction together with CDI. Repeated brain MRI examinations are also useful for detecting the early signs of CDI and/or ND disease. Once the precise diagnosis of CDI has been made, nasal or oral DDAVP is a safe therapeutic option that effectively controls CDI. Patients with anterior pituitary dysfunction require other hormonal replacement therapies.

Effective measures that can reverse CDI or other CDI-related neurological complications, or prevent them from newly occurring, remain elusive. Studies have shown that in $\mathrm{LCH}-$ induced CDI cases, the CDI is already present at the start of chemotherapy in half of the cases, while the remaining half develop CDI during chemotherapy or after off therapy. Ideally, the early introduction of chemotherapy should be able to reverse pre-existing CDI and prevent the new occurrence of CDI. Unfortunately, however, therapeutic regimens for patients with $\mathrm{LCH}$ that consistently achieve these goals have not yet been identified. However, we recently found that IVIG may be able to prevent the progression of ND 
disease in patients with LCH $(\mathbf{1 0}, \mathbf{3 5})$. Given this observation and the fact that IVIG is also effective for other CNS inflammatory diseases, we have hypothesized that pre-emptive measures that include high dose IVIG may reduce the incidence of LCH-related CNS diseases, namely CDI and its related neurological complications, if they are given early and are combined with chemotherapy. To that end, we have proposed that the initial treatment of patients with "CNS-risk"-LCH should contain a high dose $(2 \mathrm{~g} / \mathrm{kg} /$ dose $)$ of IVIG combined with conventional induction chemotherapy (40). However, precise efficacy of immunomodulatory agents such as IVIG for treating LCH, particularly for preventing the development of LCH-related CNS diseases, needs to be explored by future studies.

\section{References}

[1] Maghnie M, Cosi G, Genovese E, et al. Central diabetes insipidus in children and young adults.N Engl J Med 2000;343:998-1007.

[2] Adam Z, Balsíková K, Krejcí M, et al.Central diabetes insipidus in adult patients--the first sign of Langerhans cell histiocytosis and Erdheim-Chester disease. Three case studies and literature review.Vnitr Lek.2010; 56:138-148.

[3] Grois N, Fahrner B, Arceci RJ, et al. Central nervous system disease in Langerhans cell histiocytosis. J Pediatr.2010;156:873-881.

[4] Abla O, Egeler RM, Weitzman S. Langerhans cell histiocytosis: Current concepts and treatments. Cancer Treat Rev. 2010; 36:354-359.

[5] Grois N, Pötschger U, Prosch H, et al. Risk factors for diabetes insipidus in Langerhans cell histiocytosis. Pediatr Blood Cancer 2006; 46: 228-233.

[6] Leger J, Velasquez A, Garel C, et al. Thickened pituitary stalk on magnetic resonance imaging in children with central diabetes insipidus. J Clin Endocrinol Metab.1999; 84:1954-1960.

[7] Grois N, Prayer D, Prosch H, et al. Course and clinical impact of magnetic resonance imaging findings in diabetes insipidus associated with Langerhans cell histiocytosis. Pediatr Blood Cancer 2004;43:59-65.

[8] Lee MH, Choi HY, Sung YA, Lee JK.High signal intensity of the posterior pituitary gland on T1-weighted MR images. Correlation with plasma vasopressin concentration to water deprivation. ActaRadiol. 2001; 42:129-134.

[9] Wnorowski M, Prosch H, Prayer D, et al. Pattern and course of neurodegeneration in Langerhans cell histiocytosis. J Pediatr 2008; 153:127-132

[10] Imashuku S, Shioda Y, Kobayashi R, et al. Neurodegenerative central nervous system disease as late sequelae of Langerhans cell histiocytosis. Report from the Japan LCH Study Group.Haematologica.2008; 93:615-618.

[11] Dunger DB, Broadbent V, Yeoman E, et al. The frequency and natural history of diabetes insipidus in children with Langerhans cell histiocytosis. N Engl J Med 1989; 321:1157-1162.

[12] Imashuku S, Kinugawa N, Matsuzaki A, et al. Langerhans cell histiocytosis with multifocal bone lesions: comparative clinical features between single and multisystems.Int J Hematol 2009; 90:506-512.

[13] Broadbent V, Pritchard J. Diabetes insipidus associated with Langerhans cell histiocytosis: is it reversible? Med Pediatr Oncol 1997;28: 289-293.

[14] Matoussi N, Aissa K, Fitouri Z, et al. Central diabetes insipidus: diagnostic difficulties. Ann Endocrinol (Paris). 2008 ;69:231-239. 
[15] Donadieu J, Egeler RM, Pritchard J. Langerhans cell histiocytosis: a clinical update. In (Edit by Weitzman and Egeler RM) Histiocytic Disorders of Children and Adults; Basic Science, Clinical Features and Therapy (Cambridge University Press 2005), pp95-129

[16] Schmitt S, Wichmann W, Martin E, et al. Pituitary stalk thickening with diabetes insipidus preceding typical manifestations of Langerhans cell histiocytosis in children. Eur J Pediatr.1993;152:399-401.

[17] Prosch H, Grois N, Bökkerink J, et al. Central diabetes insipidus: Is it Langerhans cell histiocytosis of the pituitary stalk? A diagnostic pitfall. Pediatr Blood Cancer 2006; 46:363-366

[18] Conley A, Manjila S, Guan H, et al. Non-Langerhans cell histiocytosis with isolated CNS involvement: An unusual variant of Erdheim-Chester disease. Neuropathology. 2010; 30: 634-647

[19] Abe T. Lymphocytic infundibulo- neurohypophysitis and infundibulo-panhypophysitis regarded as lymphocytic hypophysitis variant. Brain Tumor Pathol.2008; 25: 59-66.

[20] Arslan A, Karaarslan E, Dincer A.High intensity signal of the posterior pituitary. A study with horizontal direction of frequency-encoding and fat suppression MR techniques.ActaRadiol.1999; 40:142-145.

[21] Lin KD, Lin JD, Hsu HH, et al. Endocrinological aspects of Langerhans cell histiocytosis complicated with diabetes insipidus. J Endocrinol Invest.1998;21:428-433.

[22] Modan-Moses D, Weintraub M, Meyerovitch J, et al. Hypopituitarism in Langerhans cell histiocytosis: seven cases and literature review. J Endocrinol Invest.2001; 24: 612-617.

[23] Kaltsas, GA,Powles TB, Evanson J, et al. Hypothalamo-pituitary abnormalities in adult patients with Langerhans cell histiocytosis: clinical, endocrinological, and radiological features and response to treatment. J ClinEndocrinolMetab 2000; 85: 1370-1376

[24] Amato MC, Elias LL, Elias J, et al. Endocrine disorders in pediatric - onset Langerhans Cell Histiocytosis. Horm Metab Res 2006; 38: 746-751

[25] Donadieu J, Rolon MA, Pion I, et al. Incidence of growth hormone deficiency in pediatric-onset Langerhans cell histiocytosis: Efficacy and safety of growth hormone treatment. J Clin Endocrinol Metab 2004; 89:604-609.

[26] Ottaviano F, Finlay JL. Diabetes insipidus and Langerhans cell histiocytosis: a case report of reversibility with 2-chlorodeoxyadenosine. J Pediatr Hematol Oncol. 2003;25: 575-577.

[27] Minehan KJ, Chen MG, Zimmerman D, et al. Radiation therapy for diabetes insipidus caused by Langerhans cell histiocytosis. Int J Radiat Oncol Biol Phys. 1992; 23: 519524.

[28] Greenberger JS. Radiation therapy in children continued need to assess risk versus gain. Int J Radiat Oncol Biol Phys. 1992; 23: 675-676.

[29] Rosenzweig KE, Arceci RJ, Tarbell NJ.Diabetes insipidus secondary to Langerhans' cell histiocytosis: is radiation therapy indicated? Med Pediatr Oncol 1997; 29:36-40.

[30] Abla O, Weitzman S, Minkov M, et al. Diabetes insipidus in Langerhans cell histiocytosis: When is treatment indicated? Pediatr Blood Cancer 2009; 52:555-556. 
[31] Fukuda I, Hizuka N, Takano K.Oral DDAVP is a good alternative therapy for patients with central diabetes insipidus: experience of five-year treatment. Endocr J. 2003; 50: 437-443.

[32] Rivkees SA, Dunbar N, Wilson TA. The management of central diabetes insipidus in infancy: desmopressin, low renal solute load formula, thiazide diuretics. J Pediatr Endocrinol Metab 2007;20:459-469.

[33] Makras P, Papadogias D, Kontogeorgos G, et al. Spontaneous gonadotrophin deficiency recovery in an adult patient with Langerhans cell histiocytosis (LCH).Pituitary2005;8:169-174.

[34] Dhall G, Finlay JL, Dunkel IJ, et al. Analysis of outcome for patients with mass lesions of the central nervous system due to Langerhans cell histiocytosis treated with 2chlorodeoxyadenosine. Pediatr Blood Cancer 2008; 50:72-79.

[35] Imashuku S Treatment of Neurodegenerative CNS Disease in Langerhans Cell Histiocytosis, with a Combination of Intravenous Immunoglobulin and Chemotherapy. Pediatr Blood Cancer 2008;50:308-311

[36] Idbaih A, Donadieu J, Barthez, MA, et al. Retinoic Acid Therapy in "DegenerativeLike" Neuro-Langerhans Cell Histiocytosis: A Prospective Pilot Study. Pediatr Blood Cancer 2004; 43:55-58

[37] Allen CE, Flores R, Rauch R, et al. Neurodegenerative central nervous system Langerhans cell histiocytosis and coincident hydrocephalus treated with vincristine/cytosine arabinoside. Pediatr Blood Cancer 2010;54:416-423.

[38] Imashuku S, Okazaki NA, Nakayama M, et al.VCR/AraC Chemotherapy and ND-CNSLCH. Pediatr Blood Cancer 2008; 50: 308-311.

[39] ShiodaY, Adachi S, Imashuku S, et al. Analysis of 43 cases of Langerhans cell histiocytosis $(\mathrm{LCH})$ - induced central diabetes insipidus registered in the JLSG-96 and JLSG -02 studies in Japan (in preparation)

[40] Imashuku S. High dose immunoglobulin (IVIG) may reduce the incidence of Langerhans cell histiocytosis (LCH)-associated central nervous system involvement.CNS Neurol Disord Drug Targets.2009; 8:380-386. 


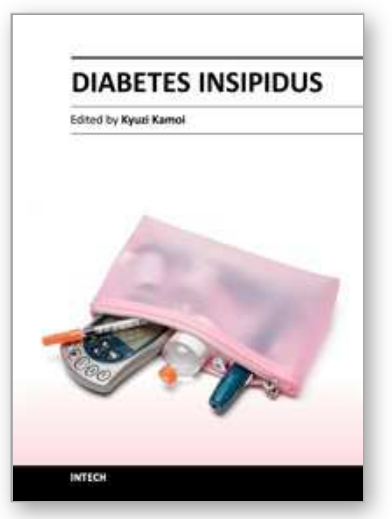

\author{
Diabetes Insipidus \\ Edited by Prof. Kyuzi Kamoi
}

ISBN 978-953-307-367-5

Hard cover, 140 pages

Publisher InTech

Published online 14, November, 2011

Published in print edition November, 2011

The first chapter of the book reports on the management of Langerhans cell histiocytosis (LCH)-induced central diabetes insipidus and its associated endocrinological/neurological sequelae in the national survey. The next chapter addresses DI and head injuries. Next, the management of neuroendocrine instability during maintenance of potential organ donors is described. Organ transplants have gradually increased worldwide. To have maintenance of appropriate potential organs, AVP is needed. Furthermore, nephrogenic DI-the potential therapeutic drugs and analysis of membrane protein stability is the topic of the next two chapters, followed by new insights into the diagnosis and management of pregnancy-related DI. The seventh chapter reports on the problems with differential diagnosis in a case of central DI in a female patient with bipolar disorder. The lithium treatment usually resulted in nephrogenic DI. Finally, over the last years, the development of MRI imaging on the pituitary gland with the stalk and hypothalamus has advanced. The final chapter interprets imaging techniques in DI in detail.

\title{
How to reference
}

In order to correctly reference this scholarly work, feel free to copy and paste the following:

Shinsaku Imashuku and Akira Morimoto (2011). Management of Langerhans Cell Histiocytosis (LCH)-Induced Central Diabetes Insipidus and Its Associated Endocrinological/Neurological Sequelae, Diabetes Insipidus, Prof. Kyuzi Kamoi (Ed.), ISBN: 978-953-307-367-5, InTech, Available from: http://www.intechopen.com/books/diabetes-insipidus/management-of-langerhans-cell-histiocytosis-lchinduced-central-diabetes-insipidus-and-its-associate

\section{INTECH}

open science | open minds

\section{InTech Europe}

University Campus STeP Ri

Slavka Krautzeka 83/A

51000 Rijeka, Croatia

Phone: +385 (51) 770447

Fax: +385 (51) 686166

www.intechopen.com

\section{InTech China}

Unit 405, Office Block, Hotel Equatorial Shanghai

No.65, Yan An Road (West), Shanghai, 200040, China 中国上海市延安西路65号上海国际贵都大饭店办公楼 405 单元

Phone: +86-21-62489820

Fax: $+86-21-62489821$ 
(C) 2011 The Author(s). Licensee IntechOpen. This is an open access article distributed under the terms of the Creative Commons Attribution 3.0 License, which permits unrestricted use, distribution, and reproduction in any medium, provided the original work is properly cited. 